\title{
PENGGUNAAN MEDIA SOSIAL TERHADAP KEJADIAN DEPRESI, KECEMASAN DAN STRES PADA MAHASISWA
}

\section{USE OF SOCIAL MEDIA ON EVENTS OF DEPRESSION, ANXIETY AND STRESS AMONG UNIVERSITY STUDENTS}

\author{
Syiddatul Budury ${ }^{1}$, Andikawati Fitriasari ${ }^{2}$ Khamida $^{3}$ \\ 1,2,3 Fakultas Keperawatan dan Kebidanan Universitas Nahdlatul Ulama Surabaya
}

\begin{abstract}
ABSTRAK
Penggunaan media sosial dengan intensitas yang tinggi adalah hal yang sekarang lagi terjadi di kalangan remaja, mereka berinteraksi satu sama lain melalui media sosial, hal ini memicu terjadinya beberapa masalah kesehatan, tidak hanya fisik tapi juga kesehatan mental. Tujuan dari penelitian ini adalah untuk mengidentifikasi pengaruh penggunaan media sosial terhadap kejadian depresi, kecemasan dan stress pada mahasiswa. Desain penelitian ini adalah analitik cross sectional dengan jumlah sampel sebanyak 80 mahasiswa yang diambil secata simple random sampling, variable indepennya adalah penggunaan media sosial, variable dependen adalah depresi, kecemasan dan stress. Data diambil dengan menggunakan social media addiction scale, dan depression, anxiety, stree scale, (DASS 21) dan diolah dengan menggunakan uji multivariate Manova. Hasil penelitian menunjukkan bahwa 65 mahasiswa (81.5\%) adalah medium user, 9 mahasiswa (11.5\%) sebagai light user dan 6 mahasiswa (7.5\%) sebagai heavy user. Hasil uji Manova didapatkan $P$ value pada variable depresi sebesar 0.03 , kecemasan dengan $p$ value 0.04 dan stress dengan $p$ value 0.02 . Hasil ini menunjukkan bahwa terdapat pengaruh penggunaan media sosial terhadap terjadinya depresi, kecemasan dan stress pada mahasiswa.
\end{abstract}

Kata kunci : Media sosial, Depresi, Kecemasan, Stress.

\section{ABSTRACT}

The use of Social media with high intensity is happening in adolescence. They are interacting each other by social media. This triggers health problems, not only physical but also mental health. The aims of this research was to analyze the effect of the use of social media on depression, anxiety and stress among university students. the research design was cross sectional study, and the sample was 80 students taken by simple random sampling. independent variable was social media usage and dependent variable were depression, anxiety and stress. The data was taken using social media addiction scale, and depression, anxiety, stress scale (DASS 21). it was analyzed by using Manova statistic test. the result showed that 65 students (81.5) was medium user, 9 students (11.5\%) light user and 6 students (7.5\%) as heavy user. the Manova test showed that P Value at Depression was 0.03, Anxiety got 0.04 and the $p$ Value for stress was 0.02. it means that there was effect of social media use to depression, anxiety and stress.

Balimedikajurnal.com 
BMJ. Vol 6 No 2, 2019: 205-208

ISSN : 2615-7047

DOI: https://doi.org/10.36376/bmj.v6i2

Keywords : Social media, Depression, Anxiety, Stress

\begin{tabular}{ll}
\hline Alamat Korespondensi & : Unusa Kampus A Jl. Smea No. 57 Surabaya \\
Email & syiddatbr@unusa.ac.id \\
\hline
\end{tabular}

\section{PENDAHULUAN}

Media sosial adalah suatu interaksi sosial antara individu dalam berbagi dan bertukar informasi. Media sosial dapat mencakup berbagai ide, pendapat, gagasan dan konten dalam komunitas virtual serta mampu menghadirkan dan mentranslasikan cara berkomunikasi baru dengan teknologi yag sama sekali berbeda dari media tradisional (1) Bagi generasi Z, yaitu mereka yang lahir periode 1996-2010 (2), memiliki akun di media sosial seolah sebuah keharusan, selain untuk media pembelajaran juga sebagai wujud eksistensi dari keberadaan diri mereka. Selalu ada dua sisi dari sebuah hal, termasuk penggunaan media sosial bagi remaja, salah satu dampak negatif yang bisa muncul adalah kecanduan untuk selalu membuka gawai. Hal lainnya adalah keinginan untuk bisa mengunggah foto terbaik dari dirinya sehingga mendapatkan pujian atau likes yang banyak membuat perilaku berswafoto makin marak, tekanan untuk menampilkan hal terbaik dari dirinya bisa membuat remaja cemas, ditambah mereka sering membuka profil teman atau selebritis yang mereka ikuti jejaringnya di media sosial. Selain cemas, pencapaian yang diraih temannya yang dilihat di halaman media sosialnya akan membuat remaja membandingkan kondisi dirinya dengan tokoh atau teman tersebut yang akan berpengaruh pada kondisi kesehatan mental seperti kecemasan, depresi dan harga diri remaja.

Penggunaan media sosial yang berlebihan akan berpotensi terjadinya masalah kesehatan mental seperti depresi, cemas, stress, risiko bunuh diri dan gangguan konsep diri (3) Penelitian lain yang dilakukan oleh Cepoiou (4) menyebutkan bahwa depresi adalah hal yang paling mungkin terjadi pada mereka yang menggunakan media sosial dengan itensitas yang tinggi.

\section{METODE PENELITIAN}

Penelitian ini dilakukan pada mahasiswa Universitas Nahdlatul Ulama Surabaya pada periode September - Oktober 2019. Desain yang digunakan adalah analitik cross sectional dengan sampel adalah mahasiswa S1 keperawatan semester 5 sebanyak 80 mahasiswa yang diambil secara simple random sampling, data diambil menggunakan kuesioner yaitu Social Media Addiction Scale dan Depression, Anxiety, Stress Scale (DASS 21). Data dianalisis dengan menggunakan uji statistik multivariat Manova.

Balimedikajurnal.com 
BMJ. Vol 6 No 2, 2019: 205-208

ISSN : $2615-7047$

DOI: https://doi.org/10.36376/bmj.v6i2

Hasil

\section{HASIL DAN PEMBAHASAN}

Tabel 1

Distribusi karakteristik mahasiswa

\begin{tabular}{ccc}
\hline Usia & F & $\mathbf{\%}$ \\
\hline 19 Tahun & 13 & 16.3 \\
20 Tahun & 44 & 55 \\
21 Tahun & 17 & 21.3 \\
22 Tahun & 6 & 7.5
\end{tabular}

\begin{tabular}{ccc}
\hline Jenis Kelamin & & \\
\hline Laki-laki & 6 & 7.5 \\
Perempuan & 74 & 92.5 \\
\hline Suku & & \\
& & 85 \\
Jawa & 68 & 8.8 \\
Madura & 7 & 6.3 \\
Sunda & 5 & \\
\hline
\end{tabular}

Tabel 2

Hasil uji statistik

\begin{tabular}{cccccc}
\hline & $\begin{array}{c}\text { Penggunaan } \\
\text { Media Sosial }\end{array}$ & Mean & SD & N & Sig. \\
\hline Depresi & Light User & 1.222 & 0.666 & 9 & \\
& Medium User & 2.584 & 1.935 & 65 & 0.03 \\
& Heavy User & 5.000 & 3.687 & 6 & \\
\hline Kecemasan & Light User & 4.222 & 2.488 & 9 & \\
& Medium User & 6.000 & 3.292 & 65 & 0.04 \\
& Heavy User & 5.500 & 4.037 & 6 & \\
\hline \multirow{2}{*}{ Stres } & Light User & 3.555 & 1.424 & 9 & \\
& Medium User & 4.815 & 2.822 & 65 & 0.02 \\
& Heavy User & 9.000 & 4.857 & 6 & \\
\hline
\end{tabular}

Dari tabel 2 kita dapatkan bahwa $P$ value dari masing-masing variabel lebih kecil dari 0.05 sehingga bisa disimpulkan bahwa penggunaan media sosial berpenagruh terhadap terjadinya depresi, kecemasan dan stres mahasiswa.

\section{Pembahasan Hasil}

Hasil penelitian menunjukkan bahwa mayoritas pengguna media sosial adalah medium user, yaitu mahasiswa yang menggunakan media sosial dengan intensitas 2- 4 Jam perhari, kondisi ini memicu terjadinya masalah kesehatan mental seperti depresi, kecemasan dan stres, hasil penelitian ini sejalan dengan yang dilakukan oleh Younes (5) yang juga membuktikan bahwa kecanduan internet bisa menyebabkan depresi, kecemasan, stres, gangguan dan gangguan harga diri. Selain 
DOI: https://doi.org/10.36376/bmj.v6i2

aspek mental, masalah yang muncul akibat kecanduan media sosial pada mahasiswa adalah adanya gangguan pada prestasi akademik mahasiswa (6)

Depresi, kecemasan dan stres bisa muncul karena saat menggunakan media sosial memungkinkan pengguna membandingkan diri sendiri dengan orang lain, meski hanya lewat foto yang diunggah, dibanding dengan generasi milenial, generasi $\mathrm{Z}$ lebh rentan mengalami masalah kesehatan mental karena tekanan dan tuntutan sosial yang lebih tinggi, mereka tidak hanya dituntut untuk memiliki nilai yang bagus, tapi juga keharusan untuk eksis di media sosial. Depresi, stres dan kecemasan juga dipicu oleh masalah sosial dan politik, salah satunya adalah membaca berita tentang pelecehan seksual dan meningkatnya kasus bunuh diri (7)

\section{SIMPULAN DAN SARAN}

Awareness akan pentingnya kesehatan mental diri sendiri perlu ditingkatkan para remaja agar dapat meminimalisr terjadinya masalah kesehatan mental.

\section{DAFTAR PUSTAKA}

1. Terry M. Twittering healthcare: Social media and medicine. Telemed eHealth. 2009;15(6):507-10.

2. Husna N. Fenomenologi Komunikasi Generasi Z [Internet]. 2018. Available from: $\quad$ https://binus.ac.id/malang/2018/02/fenomenologi-komunikasigenerasi-z/

3. Guntuku SC, Yaden DB, Kern ML, Ungar LH, Eichstaedt JC. Detecting depression and mental illness on social media: an integrative review. Curr Opin Behav Sci. 2017;18:43-9.

4. Monica Cepoiu JMGCSBC. Recognition of Depression by Non-psychiatric Physicians-A Systematic Literature Review and Meta-analysis. J Gen Intern Med. 2008;23(1):25-36.

5. Younes F, Halawi G, Jabbour H, Osta N El, Karam L, Hajj A, et al. Internet addiction and relationships with insomnia, anxiety, depression, stress and self-esteem in university students: A cross-sectional designed study. PLoS One. 2016;11(9).

6. J. Al-Menayes J. Dimensions of Social Media Addiction among University Students in Kuwait. Psychol Behav Sci. 2015;4(1):23.

7. Dwiputra KO. Krisna Octavianus Dwiputra [Internet]. 2018. Available from: https://www.klikdokter.com/info-sehat/read/3617250/generasi-z-rentanterserang-gangguan-mental 